\title{
Biochemical approaches for nutritional support of skeletal muscle protein metabolism during sepsis
}

\author{
Thomas C. Vary* and Christopher J. Lynch \\ Department of Cellular and Molecular Physiology, Milton S. Hershey Medical Center, Penn State University College of \\ Medicine, Hershey, PA 17033, USA
}

\begin{abstract}
Sepsis initiates a unique series of modifications in the homeostasis of $\mathrm{N}$ metabolism and profoundly alters the integration of inter-organ cooperatively in the overall $\mathrm{N}$ and energy economy of the host. The net effect of these alterations is an overall $\mathrm{N}$ catabolic state, which seriously compromises recovery and is semi-refractory to treatment with current therapies. These alterations lead to a functional redistribution of $\mathrm{N}$ (amino acids and proteins) and substrate metabolism among injured tissues and major body organs. The redistribution of amino acids and proteins results in a quantitative reordering of the usual pathways of $\mathrm{C}$ and $\mathrm{N}$ flow within and among regions of the body with a resultant depletion of the required substrates and cofactors in important organs. The metabolic response to sepsis is a highly integrated, complex series of reactions. To understand the regulation of the response to sepsis, a comprehensive, integrated analysis of the fundamental physiological relationships of key metabolic pathways and mechanisms in sepsis is essential. The catabolism of skeletal muscles, which is manifested by an increase in protein degradation and a decrease in synthesis, persists despite state-of-the-art nutritional care. Much effort has focused on the modulation of the overall amount of nutrients given to septic patients in a hope to improve efficiencies in utilisation and $\mathrm{N}$ economies, rather than the support of specific end-organ targets. The present review examines current understanding of the processes affected by sepsis and testable means to circumvent the sepsis-induced defects in protein synthesis in skeletal muscle through increasing provision of amino acids (leucine, glutamine, or arginine) that in turn act as nutrient signals to regulate a number of cellular processes.
\end{abstract}

Muscle protein metabolism: Amino acid metabolism: Sepsis

\section{Introduction}

The host's response to systemic bacterial infection (sepsis) consists of multiple biological and pathological processes that depend upon the regulation of the metabolic response. One of the earliest metabolic manifestations of the host's response to sepsis is an accelerated and excessive excretion of $\mathrm{N}$, indicative of a net loss of protein. The increased $\mathrm{N}$ excretion is a marker for profound alterations in wholebody protein metabolism following trauma or infection (Wilmore, 2000). N losses of up to $17 \%$ of total body protein may be observed in septic patients despite aggressive nutritional support (for example, see Plank et al. 1998). Because skeletal muscle comprises approximately $45 \%$ of body weight, whole-body $\mathrm{N}$ balance reflects changes in protein turnover in muscle during sepsis. As such, approximately $70 \%$ of the septic-induced whole-body protein loss comes from the erosion of skeletal muscle (Plank et al. 1998). The persistent loss of large amounts of protein in sepsis leads to organ-system dysfunction and, eventually, organ failure (Keys et al. 1950).

During the past two decades considerable advances in our fundamental understanding of the biological alterations induced by sepsis have provided dramatic therapies available to the health professionals caring for critically ill patients. Given the severe metabolic disturbances initiated by the septic episode, the nutritional requirements of the injured or septic patient differ from those of the starved individual. Critically ill patients have unique nutritional needs to combat not only the muscle wasting but provide adequate substrates for wound healing, a sustained acutephase protein response, and support of the immune system.

The clinical implications of continued loss of skeletal muscle protein in septic patients include poor wound

\footnotetext{
Abbreviations: BCKD, branched-chain keto-acid dehydrogenase; CL, carbohydrate plus leucine; 4E-BP, eukaryotic initiation factor 4E binding protein; eIF, eukaryotic initiation factor; met-tRNA ${ }_{i}$ met, initiator methionyl-tRNA; mTOR, mammalian target of rapamycin.

*Corresponding author: Dr Thomas C. Vary, fax +1 717531 7667, email tvary@psu.edu
} 
healing (Cooney et al. 1997a), loss of muscle strength, diminished muscle activity (Brough et al. 1986; Boczkowski et al. 1988; Windsor \& Hill, 1988), and, if severe enough, death (Keys et al. 1950). Muscle weakness in septic patients contributes to a continued dependence on mechanical respirators, an increased risk of pneumonia, and the complications associated with extended periods of bed rest. These complications prolong hospitalisation and convalescence, thereby increasing healthcare costs (Wilmore, 2000). An overall goal of nutritional support should be to maximise the retention and accretion of protein in skeletal muscle during sepsis.

\section{Skeletal muscle protein metabolism during inflammation and sepsis}

The protein wasting observed in skeletal muscle during sepsis results from an imbalance between the rates of protein synthesis and protein degradation. The imbalance in protein metabolism can be caused by an inhibition of protein synthesis and/or an acceleration of protein degradation leading to a loss of muscle protein during sepsis. The relative contribution of changes in protein synthesis and proteolysis to the overall net catabolic state in muscle varies depending upon the severity of the septic insult. Protein degradation varies, increasing as the septic episode worsens (Breuille et al. 1998) and appears independent of the fibre composition of the muscle. In contrast, sepsis causes a preferential reduction in protein synthesis in muscles composed of fast-twitch fibres, but not in those composed of slowtwitch fibres (Vary \& Kimball, 1992; Cooney et al. 1994; Lang et al. 1996). In contrast to proteolysis, rates of protein synthesis are reduced to a similar extent regardless of the severity of the septic insult.

In muscle composed of fast-twitch fibres, the synthesis of both myofibrillar and sarcoplasmic proteins is diminished to the same extent, indicating that sepsis affects the overall process of protein synthesis (Vary et al. 1996a). As the septic process wanes, muscle protein mass and protein synthesis return toward control values (Jurasinski et al. 1995b).

Non-septic trauma also results in a decrease in protein synthesis and an increase in proteolysis in skeletal muscle. In contrast to infection, changes in proteolysis and protein synthesis are short-lived in non-septic trauma patients. With adequate nutritional support, restoration of positive $\mathrm{N}$ balance and lean body mass occurs within days of the injury. In agreement with studies in non-septic trauma patients, skeletal muscle protein synthesis is not decreased in rats with a sterile abscess (Vary \& Kimball, 1992) or by the induction of experimental inflammation (Ballmer et al. 1993), provided adequate nutrient intake is maintained. The present review will focus on the molecular alterations in protein synthesis during sepsis and describe potential nutritional modifications that could potentially enhance lean body mass during infection.

\section{Amino acids availability in the control of protein synthesis during sepsis}

The response to sepsis includes a diminution in appetite, decreased nutrient intake, and an acute mobilisation of endogenous glucose, fat, and protein stores. In terms of food intake, the effects of sepsis result in a semi-fasted state in the short term. Prolonged fasting (Garlick et al. 1975) lowers the protein content of muscles and reduces rates of protein synthesis. Therefore, a sepsis-induced anorexia may be responsible, in part, for the loss of protein. In our previous studies, control animals or rats with a sterile abscess were pair-fed to the septic rats and thus nutrient intake was the same in all groups (Vary et al. 1998a, 1999a; Svanberg et al. 2000), indicating that diminished rates of protein synthesis result from the septic response rather than prolonged food restriction.

Sepsis also decreases the plasma and skeletal muscle amino acid concentrations (Askanazi et al. 1980). Hence, decreases in skeletal muscle protein synthesis could also result from a generalised reduction in the plasma or muscle amino acid concentrations. Protein synthesis would be limited by diminished amino acid availability. However, two lines of evidence argue against this scenario. First, the $\mathrm{K}_{\mathrm{m}}$ for amino acyl-tRNA transferase, the enzyme responsible for providing amino acids to the ribosome for protein synthesis, is some 100-fold less than the intracellular concentration of amino acids in muscle. Hence, the modest reduction in the plasma and muscle amino acid concentration during sepsis would be insufficient to limit the charging of the amino acyl-tRNA transferase. Second, we have previously reported that only minor decreases in plasma and skeletal muscle amino acid concentrations are observed in septic rats at a time when protein synthesis is impaired (Vary et al. 1988a, 1989a,b). Thus, it is improbable that the reduction in amino acid concentration alone is sufficient to cause the sepsis-induced inhibition in protein synthesis and other mechanisms must be explored to understand the diminished rates of skeletal muscle protein synthesis during sepsis.

\section{Sepsis reduces $m R N A$ translation initiation in the skeletal muscle}

The synthesis of proteins is a complex process in mammalian cells (Kimball et al. 1994; Cooney et al. 1998). The process involves the association of the $40 \mathrm{~S}$ and $60 \mathrm{~S}$ ribosomal subunits, mRNA, initiator methionyl-tRNA (mettRNA $_{i}{ }^{\text {met}}$ ), other amino acyl-tRNA, cofactors (i.e. GTP, ATP), and protein factors, collectively known as eukaryotic initiation factors (eIF), elongation factors, and releasing factors, through a series of discrete reactions that lead to the translation of mRNA into proteins (Fig. 1). Translation of mRNA is comprised of three phases. These are: (a) initiation, whereby met-tRNA ${ }_{i}^{\text {met }}$ and mRNA bind to $40 \mathrm{~S}$ ribosomal subunits, followed by the subsequent binding of the $40 \mathrm{~S}$ ribosomal subunit to the $60 \mathrm{~S}$ subunit to form a ribosome complex capable of translation; (b) elongation, by which tRNA-bound amino acids are incorporated into growing polypeptide chains according to the mRNA template; (c) termination, where the completed protein is released from the ribosome.

Sepsis primarily affects the mRNA translation initiation step of protein synthesis (Table 1 ). The regulation of protein synthesis occurs predominately through changes in the abundance of ribosomes and/or translational efficiency. 
Table 1. Effects of chronic sterile abdominal inflammation and chronic abdominal sepsis on mRNA content, peptide-chain initiation and elongation and termination in skeletal muscle compared with pair-fed controls

\begin{tabular}{lcc}
\hline & Inflammation & Sepsis \\
\hline mRNA content & $\leftrightarrow$ & $\leftrightarrow$ \\
Peptide-chain initiation & $\leftrightarrow$ & $\leftrightarrow$ \\
Elongation and termination & $\leftrightarrow$ & $\leftrightarrow$
\end{tabular}

$\leftrightarrow$, No difference compared with controls; $\downarrow$, reduced compared with controls.

Alterations in the relative abundance of ribosomes are not responsible for the inhibition in skeletal muscle protein synthesis in septic rats (Vary \& Kimball, 1992; Cooney et al. 1994; Jurasinski et al. 1995b). The efficiency of translation, calculated by dividing the protein synthesis rates by the total RNA (or mRNA) content, provides an index of how rapidly the existing ribosomes synthesise protein. Sepsis induces an inhibition of protein synthesis by reducing the translational efficiency by $50 \%$ in the skeletal muscle (Vary \& Kimball, 1992; Cooney et al. 1994; Jurasinski et al. 1995b; Svanberg et al. 2000). The decrease in translational efficiency does not result from a decreased amount of mRNA in muscles from septic rats (Vary et al. 1996a).

Reductions in translational efficiency can occur by inhibiting either the initiation of mRNA translation initiation (peptide-chain initiation) or peptide-chain elongation. Sepsis does not affect the rate of peptide-chain elongation in skeletal muscle (Vary \& Kimball, 1992). Therefore, the inhibitory effects of sepsis on protein synthesis are related to derangements in mRNA translation initiation.

\section{Steps in translation initiation inhibited during sepsis}

In the first step, the $80 \mathrm{~S}$ ribosome dissociates into $40 \mathrm{~S}$ and $60 \mathrm{~S}$ ribosomal subunits (Fig. 1). In the second step, the binding of met-tRNA ${ }_{i}{ }^{\text {met }}$ to the $40 \mathrm{~S}$ subunit forms the $43 \mathrm{~S}$ pre-initiation complex. In the third step, mRNA binds to the $43 \mathrm{~S}$ pre-initiation complex and forms the $48 \mathrm{~S}$ pre-initiation complex. In the fourth step, the $60 \mathrm{~S}$ ribosomal subunit associates with the $48 \mathrm{~S}$ pre-initiation complex leading to the formation of an $80 \mathrm{~S}$ ribosome capable of carrying out the elongation phase of protein synthesis.

Two steps in translation initiation have been identified as the major regulatory points in the overall control of protein synthesis (Fig. 1). The first one is the binding of met-tRNA $_{i}{ }^{\text {met }}$ to the $40 \mathrm{~S}$ ribosomal subunit to form the $43 \mathrm{~S}$ pre-initiation complex. This reaction is mediated by eIF2 and is regulated by the activity of another eIF, eIF2B. The second regulatory step involves the binding of mRNA to the $43 \mathrm{~S}$ pre-initiation complex, which is mediated by eIF4F. Sepsis inhibits both these regulatory steps involved in mRNA translation initiation (Vary \& Kimball, 1992; Cooney et al. 1994; Jurasinski et al. $1995 b$; Vary et al. 1996b, 1998b; Voisin et al. 1996; Svanberg et al. 2000).

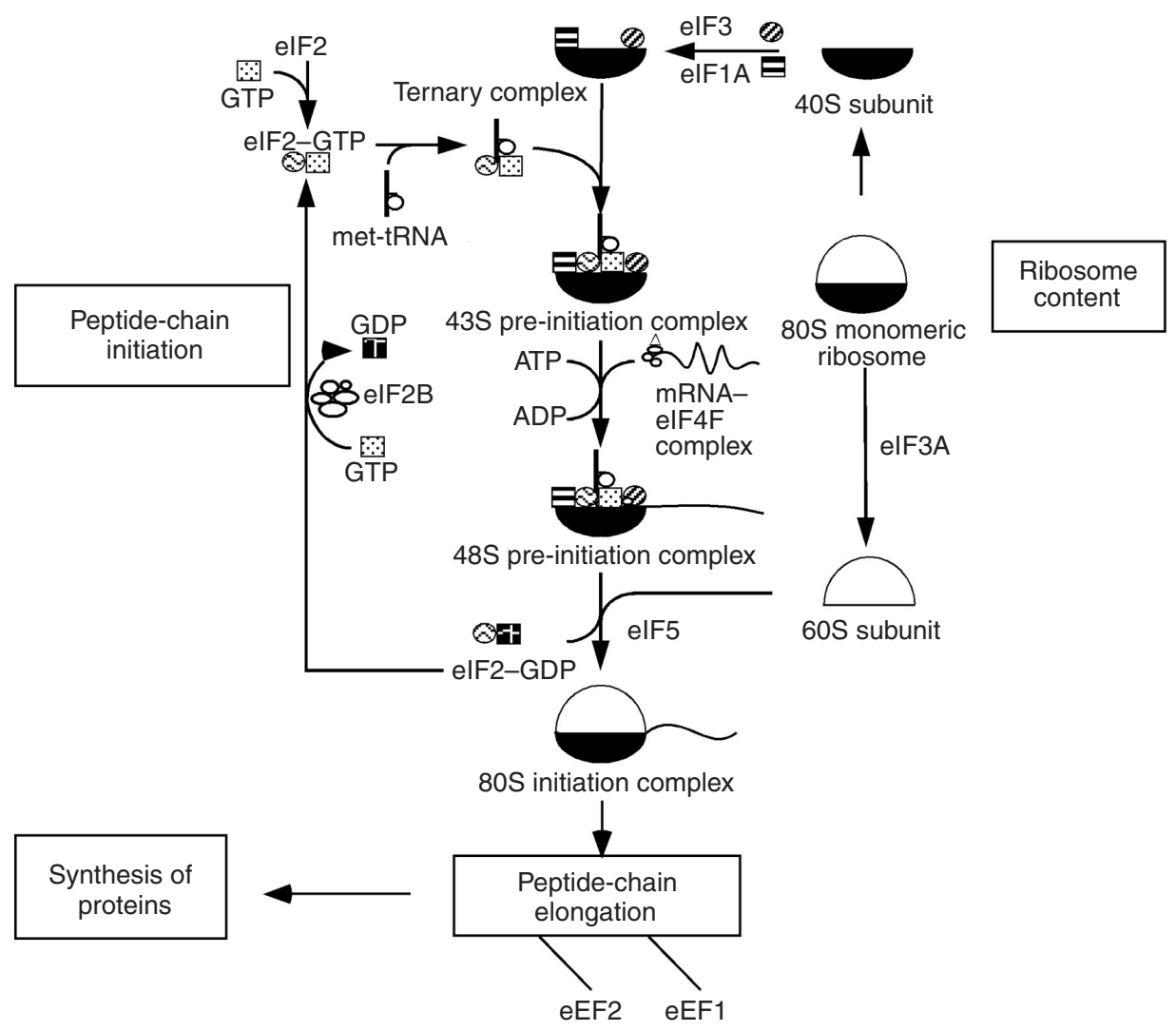

Fig. 1. Overview diagram of protein synthesis in skeletal muscle. eEF, eukaryotic elongation factor; elF, eukaryotic initiation factor; met-tRNA, methionyl-tRNA. (Adapted from Kimball \& Jefferson, 1991.) 


\section{Altered eukaryotic initiation factor 2B activity limits mRNA translation initiation in skeletal muscle during sepsis}

Sepsis reduces the first regulated reaction in translation initiation, namely the assembly of the $43 \mathrm{~S}$ pre-initiation complex (Vary et al. 1998b) (Fig. 1). Assembly of a 43S pre-initiation complex is mediated by eIF2 (Kimball \& Jefferson, 1988; Karinch et al. 1993; Vary et al. 1994). Two mechanisms regulate this process. First, the amount of eIF2 in the cell may be altered. In this regard, the cellular content of eIF2 correlates with rates of protein synthesis in non-muscle tissues (Kimball et al. 1992; Vary et al. 1994). In contrast, the cellular content of eIF2 is not significantly decreased in skeletal muscle from septic rats (Vary et al. 1994, 1996b). Second, the activity of eIF2 is regulated through the eIF2B-mediated recycling of GTP for GDP on eIF2 (Kimball \& Jefferson, 1988; Karinch et al. 1993; Vary et al. 1994). Inhibition of eIF2B activity prevents the recycling of guanine nucleotides and limits eIF2-GTP availability to form the ternary complex, thereby limiting translation initiation.

Sepsis decreases the activity of eIF2B in muscle (Vary et al. 1994, 1998b). The decrease in eIF2B activity is observed only in muscles composed of fast-twitch fibres (gastrocnemius and psoas) and not in muscles composed of slow-twitch fibres (soleus) (Vary et al. 1994), consistent with the inhibition of protein synthesis (Vary \& Kimball, 1992). The mechanism responsible for the inhibition of eIF2B activity is not known. The best-characterised mechanism controlling eIF2B is through the phosphorylation of eIF2 on its $\alpha$ subunit (Levin et al. 1976). Phosphorylation of eIF $2 \alpha$ converts the protein from a substrate into a competitive inhibitor of eIF2B (Levin et al. 1976; Scorsone et al. 1987; Dholaka \& Wabba, 1988), thereby limiting the ability of eIF2B to exchange GDP (Levin et al. 1976; Scorsone et al. 1987; Dholaka \& Wabba, 1988). However, the extent of eIF2 $\alpha$ phosphorylation is not significantly altered in the skeletal muscle from septic rats (Vary et al. 1994) (Table 2). eIF2B is also subject to allosteric regulation (Dholaka \& Wabba, 1988; Oldfield \& Proud, 1992; Karinch et al. 1993; Singh et al. 1994). Inactivation of eIF2B by $\mathrm{NAD}^{+}$and $\mathrm{NADP}^{+}$is reversed by the addition of equimolar amounts of NADH or NADPH (Dholaka \& Wabba, 1988; Karinch et al. 1993). However, we have shown that the NADPH:NADP ${ }^{+}$concentration ratio is not significantly altered in the gastrocnemius of septic rats (Vary et al. 1998b). The diminished eIF2B activity does not relate to changes in the redox state during sepsis. Thus other mechanisms regulate eIF2B activity in skeletal muscle during sepsis.

Reducing the muscle eIF2B content could account for a reduced eIF2B activity during sepsis. The cellular content of eIF2B is reduced in chronic sepsis (Vary et al. 1996b; Voisin et al. 1996) (Table 2) and returns to control values as the animals recover from septic insult. However, eIF2B protein content is not increased in acute studies where protein synthesis in the gastrocnemius from septic rats is augmented (Jurasinski et al. 1995a; Jurasinski \& Vary, 1995). Thus, reduced eIF2B protein content can be overridden and, thus, other mechanisms may be involved.
Table 2. Comparison of the changes in the eukaryotic initiation factor (elF) 2 and elF4F system in control of peptide-chain initiation in skeletal muscle during inflammation and sepsis

\begin{tabular}{lcc}
\hline & Inflammation & Sepsis \\
\hline elF2 system & $\leftrightarrow$ & $\leftrightarrow$ \\
elF2 content & $\leftrightarrow$ & $\leftrightarrow$ \\
elF2 phosphorylation & $\leftrightarrow$ & $\downarrow$ \\
elF2B activity & $\leftrightarrow$ & $\uparrow$ \\
elF2B content & $\leftrightarrow$ & $\uparrow$ \\
elF2B phosphorylation & & $\uparrow$ \\
elF4F system & $\leftrightarrow$ & $\leftrightarrow$ \\
elF4E content & $\leftrightarrow$ & $\leftrightarrow$ or \\
elF4G content & $\leftrightarrow$ & $\downarrow$ \\
elF4E phosphorylation & $\leftrightarrow$ & $\uparrow$ \\
4E-BP1 phosphorylation & $\leftrightarrow$ & $\downarrow \downarrow$ \\
4E-BP1 associated with elF4E & $\leftrightarrow$ & \\
elF4G associated with elF4E & $\leftrightarrow$ & $\leftrightarrow$ \\
\hline
\end{tabular}

4E-BP, eukaryotic initiation factor 4E binding protein; $\leftrightarrow$, no difference compared with controls; $\downarrow$, reduced compared with controls; $\uparrow$, increased compared with controls.

* Depends upon the severity of the septic episode.

eIF2B undergoes reversible phosphorylation. An increased phosphorylation is associated with an inhibition of eIF2B activity. In this regard, sepsis increases eIF2B kinase activity by $175 \%$ (Table 2). As a result of the increased eIF2B kinase activity, the phosphorylation state of the epsilon subunit of eIF2B (eIF2Bå) is increased during sepsis.

\section{mRNA recruitment to ribosomes by eukaryotic initiation factor $4 \mathrm{E}$ is impaired in skeletal muscle during sepsis}

Another rate-controlling step in the process of peptidechain initiation involves the recognition, unwinding and binding of mRNA to the 40S ribosomal subunit (Fig. 1). This step is catalysed by the multi-subunit complex of eukaryotic factors eIF4F (Rhoads, 1993; Rhoads et al. 1994; Sonenberg, 1994). eIF4F is composed of (1) eIF4A (an RNA helicase that functions with eIF4B to unwind secondary structures in the $5^{\prime}$ untranslated region of mRNA), (2) eIF4E (a protein that binds directly to the $\mathrm{m}^{7}$ GTP cap structure present at the $5^{\prime}$ end of most eukaryotic mRNA), and (3) eIF4G (a protein that functions as a scaffold for eIF4E, eIF4A and the mRNA and the ribosome). eIF4G appears to be the nucleus around which the initiation complex forms, because it has binding sites not only for eIF4E but also for eIF4A and eIF3 (Lamphear et al. 1995). eIF4E is the least abundant initiation factor in most cells. eIF4E activity plays a critical role in determining global rates of mRNA translation, because essentially all mammalian mRNA contain the $\mathrm{m}^{7} \mathrm{GTP}$ cap structure at their $5^{\prime}$ ends. eIF4E is regulated by alterations in either its availability or phosphorylation (Morley \& Traugh, 1989, 1990; Rhoads, 1993; Sonenberg, 1994). Decreasing eIF4E content through transfection with anti-sense RNA causes an inhibition of protein synthesis at the level of translation initiation. However, the cellular content of eIF4E is not decreased in the gastrocnemius of septic rats (Vary \& Kimball, 2000) (Table 2). eIF4E is also regulated by 
reversible phosphorylation (Morley \& Traugh, 1989, 1990; Rhoads, 1993; Sonenberg, 1994). eIF4E is phosphorylated following activation of the MNK1 kinase. Phosphorylation of eIF4E enhances the affinity of the factor for $\mathrm{m}^{7} \mathrm{GTP}$ cap on mRNA and for eIF4G and eIF4A and correlates with enhanced rates of protein synthesis in cells in culture stimulated with mitogens, growth factors or serum (Morley \& Traugh, 1990, 1993), or transformed with ras or src oncogenes (Morley \& Traugh, 1989, 1990, 1993). Conversely, reduced phosphorylation of eIF4E correlates with an inhibition of protein synthesis with serum depletion (Duncan et al. 1987). eIF4E phosphorylation is either unchanged or decreased during sepsis.

Translation initiation may also be regulated through the formation of the eIF4E-eIF4G complex (Fig. 2). A positive linear relationship between rates of protein synthesis and the amount of eIF4G associated with eIF4E in muscle is observed in vivo (Vary et al. 2001). Although this correlation does not prove cause and effect, the relationship between protein synthesis and the amount of eIF4G associated with eIF4E is consistent with the proposed role of the eIF4G-eIF4E complex in the overall regulation of protein synthesis. The assembly of the eIF4E-eIF4G complex is significantly diminished in skeletal muscle from septic rats (Vary \& Kimball, 2000; Vary et al. 2001) (Table 2). The diminished assembly of the eIF4E-eIF4G complex is not the result of a reduced amount of eIF4G in the muscles from septic rats (Vary et al. 2001). Reduced amounts of eIF4E associated with eIF4G following chronic sepsis would be expected to diminish the association of mRNA with the ribosome, and hence limit protein synthesis.

The availability of eIF4E for binding to eIF4G is regulated, in part, through the association of eIF4E with a family of translational repressor proteins (eIF4E binding proteins; 4E-BP) (Lin et al. 1994, 1995; Pause et al. 1994; Bhandari et al. 2001) (Fig. 2). In skeletal muscle, 4E-BP1 is the predominant form of $4 \mathrm{E}-\mathrm{BP}$. When eIF4E is bound to
4E-BP1, eIF4E cannot bind to eIF4G. Consequently, the mRNA cannot bind to the ribosome (Haghihat et al. 1995), thereby inhibiting the cap-dependent translation of mRNA by physically sequestering eIF4E into an inactive 4EBP1-eIF4E complex. In muscles from control rats, eIF4E binding to $4 \mathrm{E}-\mathrm{BP} 1$ is reduced following the phosphorylation of 4E-BP by insulin through a phosphoinositol-3-phosphate kinase-dependent pathway involving signalling through protein kinase B (PKB, AKT) and mammalian target of rapamycin (mTOR) (Kimball et al. 1996, 1997 , 1998; Fig. 3). Phosphorylation of 4E-BP releases eIF4E from the 4E-BP1-eIF4E complex and allows the eIF4E-mRNA complex to bind to eIF4G and, then, to the 40S ribosome (Lin et al. 1994). Unlike muscles from controls, increased phosphorylation of 4E-BP1 and decreased eIF4E-4E-BP1 complex formation is not associated with an enhanced formation of the eIF4E-eIF4G complex in muscles from septic rats (Vary et al. 2001; Table 2). Hense sepsis alters the formation of the eIF4E-eIF4G complex through mechanisms other than eIF4E availability.

\section{Effect of elevating amino acid concentrations on protein synthesis during sepsis}

The provision of increased protein has been shown to be beneficial in several critically ill patient populations including those with burns, head injury, trauma and sepsis. Nutritional intervention is the standard of care in the USA to attenuate the sepsis-induced catabolism of muscle proteins (Stene \& Vary, 1999; Streat et al. 2000). Nutritional support generally contains a source of amino acids in the range of $1 \cdot 2-1 \cdot 5 \mathrm{~g} / \mathrm{kg}$. New nutritional formulations, including individually modified nutrients, represent a major advance in the nutritional support of septic patients which may have a substantial influence on the clinical management of these patients. Clinicians and nutritional scientists have focused not only on the quantity of nutrients administered, but also on the composition of the nutrient mix provided to septic patients.

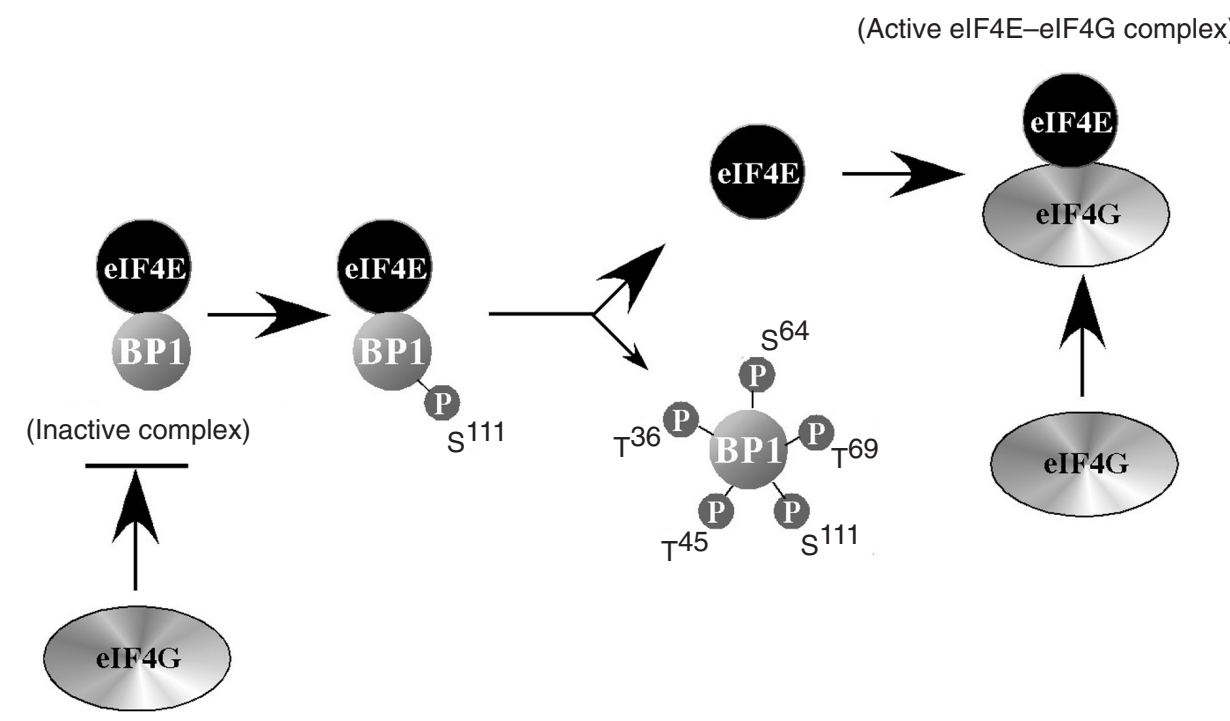

Fig. 2. Regulation of eukaryotic initiation factor (elF) 4F assembly through phosphorylation of elF4E binding protein 1 (BP1). 


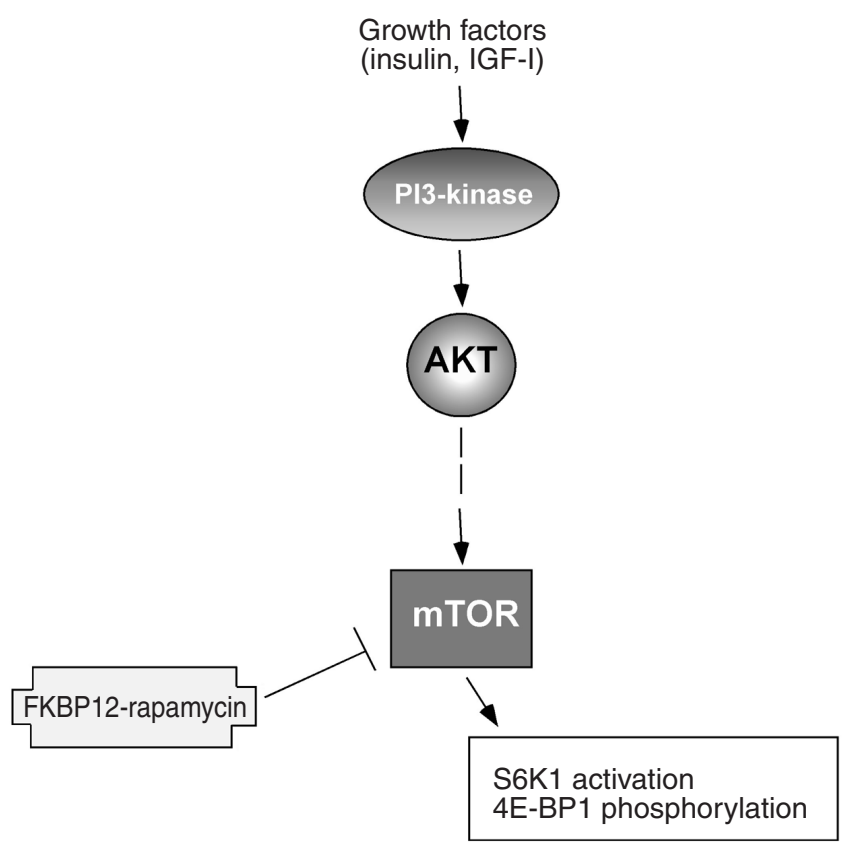

Fig. 3. Altered control of mammalian target of rapamycin (mTOR) by signal transduction pathways stimulated by hormones in phosphorylation of eukaryotic initiation factor $4 \mathrm{E}$ binding protein 1 (4E-BP1) and $70 \mathrm{kDa}$ ribosomal protein S6 kinase (S6K1). IGF, insulin-like growth factor; PI3-kinase, phosphoinositol-3-phosphate kinase; AKT, protein kinase B; FKBP, FK 506 binding protein.

Hypoaminoacidaemia is observed in both the intracellular and extracellular fluid compartments during sepsis (Askanazi et al. 1980; Jeevanandam et al. 1995; Cooney et al. 1997b). Increasing amino acid concentrations may have a stimulatory effect on protein anabolism in skeletal muscle (Vary et al. 1999b; Anthony et al. 2000a,b; Balage et al. 2001). However, information is limited regarding the ability of amino acids to stimulate protein synthesis in skeletal muscle during sepsis. Elevating the amino acid concentration in a perfused hindlimb preparation stimulated protein synthesis more than 4-fold in the gastrocnemius of septic rats and corrected the sepsis-induced defect in protein synthesis (Jurasinski et al. 1995a). In critically ill patients, elevating protein intake lessens protein losses over a $10 \mathrm{~d}$ period (Ishibashi et al. 1998). Infusion of IL-1ra into septic patients elevates the plasma concentration of eleven amino acids and total amino acid concentration was increased by $50 \%$ (Cooney et al. 1997b). Concentrations of several amino acids, including leucine, were elevated by up to 2-fold by the infusion of IL-1ra. This was associated with a decreased $\mathrm{N}$ excretion. Therefore, augmenting amino acid availability may limit the extent of protein catabolism in septic patients.

\section{Amino acids augment assembly of eukaryotic initiation factor $4 \mathrm{E}$-eukaryotic initiation factor $4 \mathrm{G}$ in skeletal muscle}

The infusion of a mixture of branched-chain amino acids improves $\mathrm{N}$ balance following trauma, an effect not mediated by alanine (Freund et al. 1979, 1980). These changes in $\mathrm{N}$ balance could result from a stimulation of protein synthesis or from an inhibition of protein degradation. In this regard, Sherwin (1978) has suggested that leucine acts through an acceleration of protein synthesis because the excretion of 3-methylhistidine (a surrogate for the breakdown of myofibrillar proteins) is unaffected by leucine, inferring that the degradation of muscle protein is not affected by leucine. Hence the effects of leucine appear to be mediated through an acceleration of protein synthesis.

The synthesis of skeletal muscle proteins is rapidly stimulated after the oral intake of nutrients. Of the nutrients provided by a complete meal, amino acids are important for enhancing protein accretion in human skeletal muscle. The concept that amino acids per se have a stimulatory effect on protein synthesis in muscle is supported by investigations utilising muscles incubated in vitro (Buse \& Reid, 1975), as well as the perfused hindlimb ( $\mathrm{Li} \&$ Jefferson, 1978; Jurasinski et al. 1995a; Vary et al. 1999b). In perfused muscles, elevating the amino acid concentrations above those of normal rat plasma stimulates protein synthesis (Li \& Jefferson, 1978; Jurasinski et al. 1995a; Vary et al. 1999b). Likewise, infusing amino acids in vivo enhances muscle protein synthesis independent of any stimulatory effect induced by changes in plasma anabolic hormone concentrations (Tessari et al. 1987; Fukagawa et al. 1988; Bennet et al. 1989, 1990; Giordano et al. 1996; Svanberg et al. 1996).

Three lines of evidence suggest that amino acids are probably not augmenting protein synthesis merely by increasing substrate availability. First, the tRNA involved in protein synthesis are essentially fully charged at the intracellular amino acid concentrations found in skeletal muscle from control or septic rats. Thus, increasing the amino acid concentration above that found in control rats would not further charge the tRNA. Second, increasing substrate availability should accelerate protein synthesis by enhancing peptide-chain elongation. However, amino acids accelerate peptide-chain initiation to a greater extent than elongation (Li \& Jefferson, 1978; Jurasinski et al. 1995a; Vary et al. 1999b; Anthony et al. 2000a, 2001). Third, the removal of leucine can prevent the overall stimulation of protein synthesis by amino acids; yet the removal of methionine is without effect (Vary et al. 1998b). Thus, amino acids affect protein synthesis in skeletal muscle independent of augmenting substrate availability.

Instead, amino acids appear to modulate the functions of various components of the protein synthetic machinery. Acute modulation of protein synthesis by amino acid availability occurs via changes in the activity of eIF4E rather than eIF2B. In perfused hindlimb, the acceleration of protein synthesis with increasing amino acid concentrations is associated with increases in the amount of eIF4G bound to eIF4E, and a corresponding decrease in the amount of eIF4E in the inactive eIF4E-4E-BP1 complex (Vary et al. $1999 b$ ). Likewise, feeding rats a meal composed of 20 or $25 \%$ protein stimulated protein synthesis and inhibited protein degradation (Yoshizawa et al. 1998; Balage et al. 2001). The stimulation of protein synthesis is also associated with an increased assembly of the active eIF4E-eIF4G complex. 


\section{Unique role of leucine in improving protein balance in skeletal muscle}

Of the amino acids, much attention has focused on the use of branched-chain amino acids for nutritional support. Branched-chain amino acids can rise to very high concentrations without adverse consequences in septic patients (Jimenez-Jimenez et al. 1991). The addition of branchedchain amino acids to total parenteral nutrition has been reported to improve $\mathrm{N}$ balance and the preservation of plasma protein concentrations. Branched-chain amino acid administration improves $\mathrm{N}$ balance during sepsis (Cerra $e t$ al. 1987; Garcia-de-Lorenzo et al. 1997) and results in a faster recovery of muscle protein (Jimenez-Jimenez et al. 1991). The parenteral administration of branched-chain amino acid-enriched $(45 \% ; 586 \mathrm{~kJ} / \mathrm{g} \mathrm{N})$ solutions improves mortality in septic patients (Garcia-de-Lorenzo et al. 1997). Branched-chain amino acids and leucine in particular intensify protein accretion in skeletal muscle. The ability of branched-chain amino acids to spare protein is not mimicked by the transamination product of leucine, $\alpha$-keto-isocaproic acid, indicating it is the amino acid rather than the metabolism of leucine that is important in modulating protein turnover (Hasselgren et al. 1988). Elevating the leucine concentration 10-fold in perfused hindlimb preparations accelerates protein synthesis by up to 2-fold (Li \& Jefferson, 1978; Vary et al. 1999b), through stimulating mRNA translation initiation.

Of the branched-chain amino acids, leucine is well suited as a nutrient signal for several reasons. First, leucine is the most potent of the branched-chained amino acids with regard to regulating protein metabolism. Second, it cannot be synthesised de novo by mammals. Third, it is the most abundant essential amino acid in dietary protein and thus is a crucial nutrient following the ingestion of a protein meal. Fourth, once taken up by the gut, leucine cannot be directly metabolised by the liver, which lacks the branched-chain amino transferase, the enzyme responsible for removal of the $\mathrm{N}$. This is in contrast to the liver's capacity to initiate the catabolism of other amino acids. In contrast to liver, most other peripheral tissues have excess capacity to catalyse this first step. This may facilitate postprandial rises in plasma leucine concentrations, as leucine would not be cleared in the first pass of the liver.

The mechanism by which leucine stimulates protein synthesis is only beginning to be elucidated, and there is no information available in experimental models of sepsis. The effect of an orally administered dose of leucine fed alone or in combination with carbohydrate on protein synthesis in the gastrocnemius was examined to better understand the role of leucine in stimulating protein synthesis in vivo (Anthony et al. 2000a). Rats were either freely fed or food deprived for $18 \mathrm{~h}$. Food-deprived rats were administered either saline, carbohydrate, leucine, or a combination of carbohydrate plus leucine (CL). Carbohydrate and CL meals were isoenergetic and provided $15 \%$ of the daily energy requirements. Leucine and CL meals each delivered $270 \mathrm{mg}$ leucine. Muscle protein synthesis was reduced by $35 \%$ in the rats administered saline compared with the freely fed rats. Lower rates of protein synthesis in the saline-administered rats were associated with a decreased hyperphosphorylation of 4E-BP1 leading to a greater association of 4E-BP1 with eIF4E and a concomitant reduction in eIF4E associated with eIF4G. The oral administration of leucine (leucine or CL), but not carbohydrate, restored protein synthesis to the values observed in the freely fed rats and resulted in a 3-fold enhanced phosphorylation of 4EBP1. Consequently, the amount of the eIF4E-4E-BP1 complex fell and the binding of eIF4E to eIF4G increased. No differences in the phosphorylation state of $\operatorname{eIF} 2 \alpha$ or the activity of eIF2B were observed among the different experimental groups.

Leucine may stimulate protein synthesis in vivo by enhancing the binding of eIF4E to eIF4G independently of increases in serum insulin. As sepsis is associated with a reduced formation of the active eIF4E-eIF4G complex, the possibility exists that leucine may increase protein synthesis during sepsis by increasing the formation of the active eIF4E-eIF4G complex.

\section{Role of mammalian target of rapamycin in leucine- induced stimulation of protein synthesis}

Leucine is a direct-acting nutrient signal that regulates protein synthesis. The effects on protein synthesis are brought about, at least in part, by the activation of a cell-signalling pathway involving the serine threonine protein kinase, mTOR (Fig. 4). In skeletal muscle, the mTOR signalling pathway appears to play a role in the stimulation of protein synthesis by growth-promoting anabolic hormones (Fig. 3). Two well-known substrates of mTOR, namely $70 \mathrm{kDa}$ ribosomal protein $\mathrm{S} 6$ kinase and the translational repressor, 4E$\mathrm{BP} 1$, are implicated in the regulation of protein synthesis. At least two signalling pathways appear to be important in leucine's acute regulation of protein synthesis, a rapamycin-sensitive pathway involving $\mathrm{mTOR}$ and an unknown rapamycinin-insensitive pathway that may or may not involve mTOR. It is presently unclear exactly how leucine activates mTOR aside from the fact that the mechanism differs from that used by insulin. For example, no leucine receptor has been yet identified. In fact, it has not been unequivocally established whether the effects of leucine are mediated by leucine or by a metabolite derived from leucine transamination, such as $\alpha$-keto-isocaproate, or by leucine oxidation (Fig. 4).

Mitochondrial metabolism may be required for the activation of mTOR by leucine. Specifically, a metabolically linked signal arising from the activation of leucine metabolism in the mitochondria results in mTOR activation (for a review, see McDaniel et al. 2002). A potential target cited is the branched-chain keto-acid dehydrogenase (BCKD) complex. The BCKD multi-enzyme complex catalyses the rate-limiting and first irreversible step in leucine oxidation. The reaction converts branchedchain $\alpha$-keto-acids (such as $\alpha$-keto-isocaproate) to CoA derivatives (such as isovaleryl CoA). This conversion is catalysed by BCKD. There are several compelling arguments in favour of the notion that BCKD kinase activities might provide a link between leucine signalling and the activation of mTOR. The first is that $\mathrm{x}$-keto-isocaproate is a physiological inhibitor of BCKD kinase. The second 


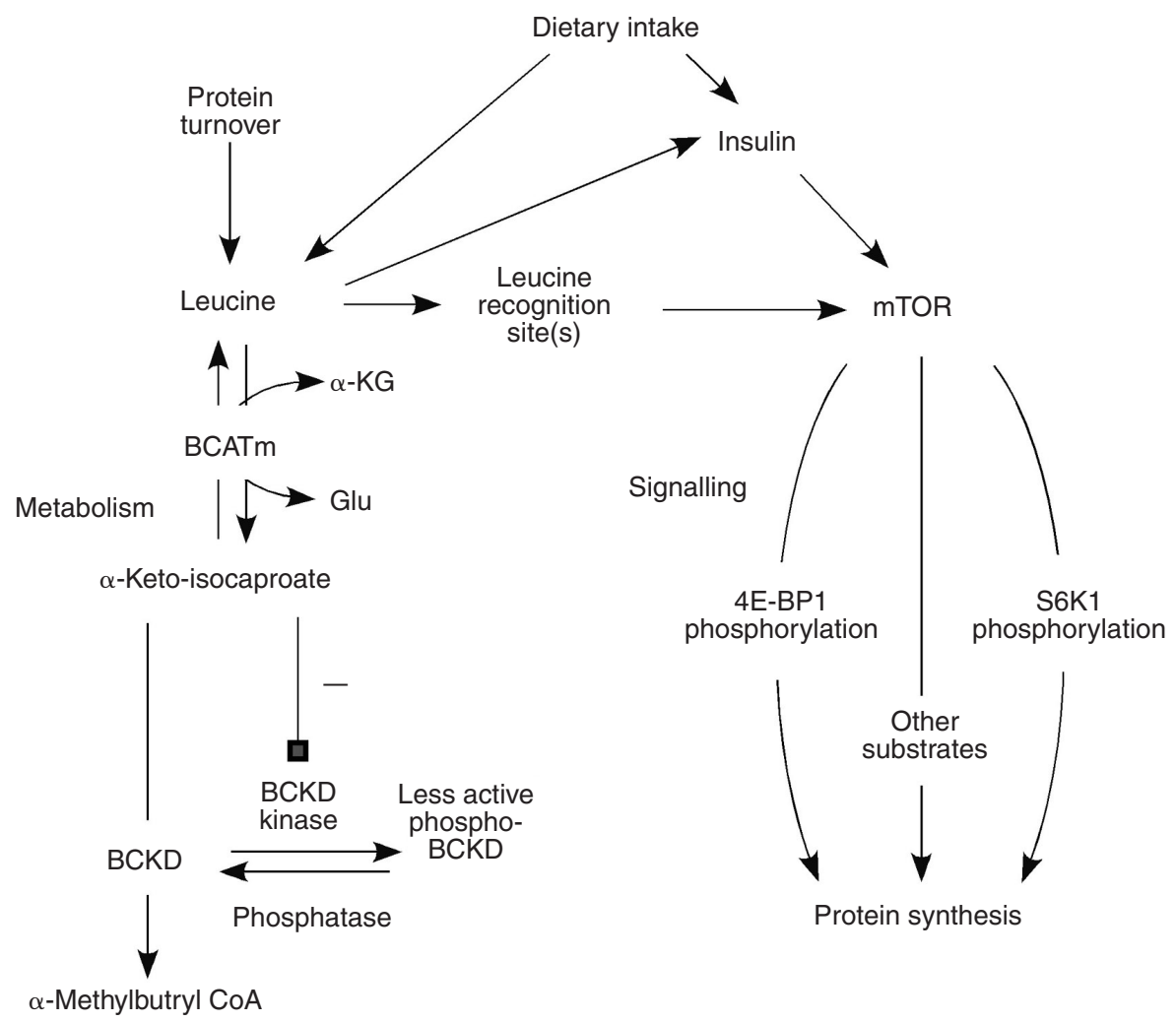

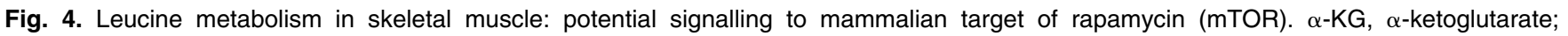
BCATm, mitochondrial branched-chain aminotransferase; Glu, glutamate; 4E-BP1, eukaryotic initiation factor 4E binding protein 1; S6K1, 70 kDa ribosomal protein S6 kinase; BCKD, branched-chain keto-acid dehydrogenase; - , inhibition of BCKD kinase by $\alpha$-keto-isocaproate.

is that the order of potency of leucine $>$ isoleucine $>$ valine and the importance of leucine in the activation of mTOR signalling (Lynch et al. 2000) is similar to that of their respective keto-acids' ability to activate the BCKD complex via inhibition of the BCKD kinase. A third observation that supports this potential mechanism is that mTOR appears to be associated with mitochondria membrane in situ. However, leucine metabolism may only be important in regulating the magnitude and duration of the signal for mTOR activation (Lynch et al. 2003). The molecular mechanism responsible for the activation of mTOR and protein synthesis by leucine remains unknown.

\section{Glutamine supplementation during sepsis}

Glutamine is the most abundant amino acid in the body, constituting upwards of $60 \%$ of the total amino acid pool. Glutamine has many diverse roles including acid-base balance, protein synthesis, $\mathrm{N}$ transport, and as an energy substrate. Glutamine functions as a carrier of $\mathrm{NH}_{3}^{+}$groups from the skeletal muscle to the liver and kidneys for the production of urea. The $\mathrm{C}$ backbone of glutamine is a source for synthesis of the key antioxidant glutathione by the liver. In addition, small-intestine mucosal cells, macrophages, fibroblasts, and lymphocytes preferentially utilise glutamine as a primary energy source. Enterocytes constitute the largest group of rapidly dividing cells in the body and hence glutamine oxidation by gut mucosal cells is substantial.

The glutamine content in proteins represents only about $15 \%$ of the amino acids, yet it accounts for over $30 \%$ of the amino acids released by muscle, indicating that substantial de novo synthesis of glutamine occurs in skeletal muscle. Almost all tissues in the body synthesise glutamine. Glutamine is synthesised from glutamate and $\mathrm{NH}_{3}{ }^{+}$by the enzyme glutamine synthase. Glutamate is not taken up appreciably by skeletal muscle and is produced within the muscle. Glutamate arises through the transamination of $\alpha$-ketoglutarate by amino acids. $\mathrm{NH}_{3}{ }^{+}$may be produced from the glutamate dehydrogenase reaction or by the deamination of AMP to inosine monophosphate catalysed by the enzyme AMP deaminase. Both these enzymes are sufficiently active to account for glutamine synthesis in skeletal muscle.

A fall in the plasma and muscle glutamine concentration is a characteristic feature of the metabolic response to trauma and sepsis (Askanazi et al. 1980; Vary et al. 1988c, 1989a). Glutamine release by muscle (Vary \& Murphy, 1989; Vary et al. 1989b) and utilisation by other cells of the body accelerates, making glutamine a conditionally essential amino acid during catabolic conditions (Lacey \& Wilmore, 1990). As such, the use of glutamine in nutritional support has been advanced (Furst et al. 1989). The 
catabolism and loss of intramuscular glutamine is attenuated by providing glutamine $(20 \mathrm{~g} / \mathrm{d})$ as a supplement to parenteral nutritional support in post-surgical patients (Stehe et al. 1989; Vinnars \& Hammervist, 1990). Initial attempts to show a similar effect with enteral feeding proved problematic as enterocytes metabolised the glutamine provided to the gut. To increase body glutamine concentrations, higher doses $(0.5 \mathrm{~g} / \mathrm{kg}$ per $\mathrm{d})$ are required (Wellbourne, 1995). Glutamine supplementation in patients undergoing elective surgery improves $\mathrm{N}$ balance, restores the plasma glutamine concentration and enhances protein synthesis. Six randomised blind studies show a decreased length of stay in post-surgical patients (for a review, see Wilmore, 2001). After blunt trauma, glutamine supplementation increased plasma glutamine concentrations, attenuated the immunosuppression, and decreased the rate of infection (for a review, see Wilmore, 2001). While a benefit of glutamine is clearly indicated in surgical or trauma patients without infection, there are several studies that fail to show an improvement in sepsis (Khan et al. 1991; Wustemann et al. 1993).

Furthermore, it is unclear that a fall in glutamine in skeletal muscle has an adverse regulatory function on protein synthesis. In rats with a sterile abscess, muscle glutamine concentrations are reduced but rates of protein synthesis are maintained (Vary et al. 1988b,c). Pharmacological reductions in skeletal muscle glutamine are not associated with changes in either whole-body or skeletal-muscle protein kinetics (OldeDiamink et al. 1999). The addition of glutamine to incubated muscle preparations does not enhance rates of protein synthesis in either control or septic rats (Fang et al. 1995; TC Vary, unpublished results). Likewise, the addition of glutamine to nutritional support offered no additional benefit on protein synthesis in skeletal muscle than amino acids alone. These observations cast doubt for a direct role of glutamine as a regulator of protein synthesis in skeletal muscle. Therefore it remains unclear whether or not intracellular glutamine concentrations are an important factor regulating protein synthesis in skeletal muscle.

Instead, a major benefit of glutamine supplementation may lie in its ability to preserve intestinal mucosal cells (Klimberg \& Souba, 1990). Glutamine administration increases villous height, stimulates small-intestine mucosa cellular proliferation and maintains small-intestine integrity (Yoshida et al. 1992; Naka et al. 1997). The reasons for these observations remain unknown. One possible explanation is that glutamine represents a major source for energy production by the cells of the small intestine. Normally, most of the glutamine is obtained from glutamine present in the lumen. However with decreased feeding associated with injury or sepsis, the amount of amino acids available to the enterocytes via the lumen is diminished. Under these conditions, most of the glutamine is obtained from the blood thereby increasing the demand for glutamine.

The loss of integrity of the intestinal mucosa has been implicated as a major factor driving bacterial translocation in sepsis. Bacterial translocation represents a pathological process by which bacteria in the gastrointestinal tract pass through the epithelial mucosa to infect the mesenteric lymph nodes and the systemic circulation. Indeed, gluta- mine supplementation attenuates the immunosuppression commonly observed following blunt trauma and decreases the rate of subsequent infection (Wilmore, 2001). By preserving the intestinal mucosa, glutamine may protect the host from bacterial translocation, limiting a potential second source of bacterial infiltration rather than directly regulating the protein synthetic machinery in skeletal muscle.

\section{Arginine supplementation during sepsis}

Like glutamine, arginine may become a conditionally essential amino acid during sepsis. Arginine has been shown to possess a potentially wide range of beneficial effects in injured or critically ill patients (Elsair et al. 1978; Barbul et al. 1990). Arginine appears to be important for tissue repair and immune-cell function. As such, the administration of arginine has been associated with maintaining T-cell function after trauma, reducing the cellular immune suppression observed after injury and enhancing collagen synthesis at the wound site. Arginine is converted to ornithine and this may be important in promoting the proliferation of enterocytes and immune cells through the subsequent metabolism of ornithine to polyamines. The conversion of arginine to ornithine may also be the mechanism by which arginine promotes wound healing. In this regard, the provision of ornithine $\alpha$-ketoglutarate in nutritional support improves gut function and prevents bacterial translocation and dissemination. These compounds may be useful in the prevention of gut-derived bacterial translocation in critically ill patients. A potential complication of arginine administration may involve the generation of NO that has both beneficial and deleterious effects during sepsis. This issue remains unresolved rather than directly regulating the protein synthetic machinery in skeletal muscle.

\section{Conclusion}

Pronounced catabolism with the loss of lean body mass is a major cause of morbidity and mortality following severe injury and sepsis. The loss of lean body mass prolongs convalescence thereby extending the duration of the illness. Optimising cardiopulmonary, immunological and nutritional support will ultimately improve survival and hopefully accelerate recovery from the septic episode. Anti-catabolic and anabolic strategies show significant clinical benefit, and the incorporation of these modalities may well improve outcomes and rates of recovery in septic patients. One aspect of this approach, namely the provision of specific amino acids in nutritional support, seems promising. The provision of amino acids with specific effects on protein synthesis may be more beneficial than simply providing a protein intake sufficient to meet protein needs. In this regard, the present review has focused on the possible beneficial role of leucine, glutamine and arginine in meeting these nutritional requirements during sepsis.

\section{Acknowledgements}

This work was supported by NIGMS grant GM-39277 (TCV) and NIDDK grants DK 62880 and DK 53843 awarded by the National Institutes of Health, USA. 


\section{References}

Anthony JC, Anthony TG, Kimball SR \& Jefferson LS (2001) Signaling pathway involved in translation control of protein synthesis in skeletal muscle by leucine. Journal of Nutrition 131, 856S-860S.

Anthony JC, Gautsch T, Kimball SR, Vary TC \& Jefferson LS (2000a) Orally administered leucine stimulates protein synthesis in skeletal muscle of postabsorptive rats in association with increased eIF4F formation. Journal of Nutrition 130, 139-145.

Anthony JC, Yoshizawa F, Anthony TG, Vary TC, Jefferson LS \& Kimball SR (2000b) Leucine stimulates translation initiation in skeletal muscle of postabsorptive rats via a rapamycin-sensitive pathway. Journal of Nutrition 130, 2413-2419.

Askanazi J, Carpenter YA, Michelson CB, Elwyn DH, Furst P, Kantrowitz LR, Gump FE \& Kinney JM (1980) Muscle and plasma amino acids following injury: influence of intercurrent infection. Annals of Surgery 192, 78-85.

Balage M, Sinaud S, Prod'Homme M, Dardevet D, Vary TC, Kimball SR, Jefferson LS \& Grizard J (2001) Amino acids and insulin are both required to regulate assembly of eIF4E-eIF4G complex in rat skeletal muscle. American Journal of Physiology 281, E565-E574.

Ballmer PE, McNurlan MA, Grant I \& Garlick PJ (1993) Responses of tissue protein synthesis to nutrient intake in rats exposed to interleukin- $1 \alpha$ or turpentine. Clinical Science 85, 337-342.

Barbul A, Larzarrow S \& Efron O (1990) Arginine enhances wound healing and lymphocyte immune response in humans. Surgery 108, 331-336.

Bennet WM, Connacher AA, Scrimgeour CM, Smith K \& Rennie MJ (1989) Increase in anterior tibialis muscle protein synthesis in healthy man during mixed amino acid infusion: studies of incorporation of $\left[1-{ }^{13} \mathrm{C}\right]$ leucine. Clinical Science 76, 447-454.

Bennet WM, Connacher AA, Scrimgeour CM \& Rennie MJ (1990) The effect of amino acid infusion on leg protein turnover assessed by $\mathrm{L}-\left[{ }^{15} \mathrm{~N}\right]$ phenylalanine and L-[1${ }^{13}$ C]leucine exchange. European Journal of Clinical Investigation 20, 41-50.

Bhandari BK, Feliers D, Duraisamy S, Stewart JL, Gingas A-C, Abbound HE, Choudhury GG, Sonenberg N \& Kasinath BS (2001) Insulin regulation of protein translation repressor 4E$\mathrm{BP} 1$, an eIF4E-binding protein, in renal epithelial cells. Kidney International 59, 866-875.

Boczkowski J, Durunil B, Branger C, Pavlovic D, Murcianao D, Pariente R \& Aubier M (1988) Effects of sepsis on diaphramatic function in rats. American Review of Respiratory Disease 138, 260-265.

Breuille D, Arnal M, Rambourdin F, Bayle G, Levieux D \& Obled C (1998) Sustained modifications of protein metabolism in various tissues in a rat model of long-lasting sepsis. Clinical Science 94, 413-423.

Brough WA, Horne G, Blout A, Irving MH \& Jeejeeboy KN (1986) Effects of nutrient intake, surgery, sepsis, and longterm administration of steroids on muscle function. British Medical Journal 293, 983-988.

Buse MG \& Reid SS (1975) Leucine. A possible regulator of protein turnover in muscle. Journal of Clinical Investigation 56, 1250-1261.

Cerra FB, Hirsh J, Mullen K, Blackburn G \& Luther W (1987) The effect of stress level, amino acid formula, and nitrogen dose on nitrogen retention in traumatic and septic stress. Annals of Surgery 205, 282-287.

Cooney R, Iocono J, Maish G, Smith JS \& Ehrlich P (1997a) Tumor necrosis factor mediates impaired wound healing in chronic abdominal sepsis. Journal of Trauma 42, 415-420.

Cooney R, Owens E, Jurasinski C, Gray K, Vannice J \& Vary T (1994) Interleukin-1 receptor antagonist prevents sepsis- induced inhibition of protein synthesis. American Journal of Physiology 267, E636-E641.

Cooney R, Pantaloni A, Sarson Y \& Vary T (1997b) A pilot study on the metabolic effects of IL-1ra in patients with severe sepsis. In 4th International Congress on Immune Consequences of Trauma, Shock, and Sepsis, pp. 909-912 [E Faist, editor]. Bologne, Italy: Mondozzi Editore S.p.A.

Cooney RN, Kimball SR \& Vary TC (1998) Regulation of skeletal muscle protein turnover during sepsis: mechanisms and mediators. Shock 7, 1-16.

Dholaka JN \& Wabba AJ (1988) Phosphorylation of the guanine nucleotide exchange factor from rabbit reticulocyte regulates its activity in polypeptide-chain initiation. Proceedings of the National Academy of Sciences USA 83, 51-54.

Duncan R, Milburn SC \& Hershey JWB (1987) Regulated phosphorylation and low abundance of HeLa cell initiation factor eIF-4F suggest a role in translational control. Heat shock effects. Journal of Biological Chemistry 262, 380-388.

Elsair J, Poly J \& Issad H (1978) Effect of arginine chlorhydrate on nitrogen balance during 3 days following routine surgery in man. Biomedicine 29, 312-318.

Fang CH, James JH, Fischer JE \& Hasselgren PO (1995) Is muscle protein turnover regulated by intracellular glutamine during sepsis? Journal of Parenteral and Enteral Nutrition 19, 279-285.

Freund H, Hoover HC Jr, Atamian S \& Fischer JE (1979) Infusion of the branched chain amino acids in postoperative patients. Anticatabolic properties. Annals of Surgery 190, 18-23.

Freund H, Yoshimura N \& Fischer JE (1980) The role of alanine in the nitrogen conserving quality of the branched-chain amino acids in the postinjury state. Journal of Surgery Research $\mathbf{2 9}$, 23-30.

Fukagawa NK, Minaker KL \& Young VR (1988) Leucine metabolism in ageing humans: effects of insulin and substrate availability. American Journal of Physiology 256, E288-E294.

Furst P, Abers S \& Stehe P (1989) Evidence for a nutritional need for glutamine in catabolic patients. Kidney International 36, 287-291.

Garcia-de-Lorenzo A, Ortiz-Leyba C, Plana M, Montejo JC, Nunez R, Ordonez FJ, Aragon C \& Jimenez FJ (1997) Parenteral administration of different amounts of branchedchain amino acids in septic patients: clinical and metabolic aspects. Critical Care Medicine 25, 418-424.

Garlick PJ, Millward DJ \& James WPT (1975) The effect of protein deprivation and starvation on the rate of protein synthesis in tissues of the rat. Biochimica et Biophysica Acta 414, 71-84.

Giordano M, Castellino P \& DeFronzo RA (1996) Differential responsiveness of protein synthesis and protein degradation to amino acid availability in humans. Diabetes 45, 393-399.

Haghihat A, Maderr S, Pause A \& Sonenberg N (1995) Repression of cap-dependent translation by 4E-binding protein I: competition with p220 for binding to eukaryotic initiation factor-4E. EMBO Journal 14, 5701-5709.

Hasselgren PO, LaFrance R, Pederson P, James JH \& Fischer JE (1988) Infusion of branched-chain amino acid-enriched solution and alpha-ketisocaproic acid in septic rats: effects on nitrogen balance and skeletal muscle protein turnover. Journal of Parenteral and Enteral Nutrition 12, 244-249.

Ishibashi N, Plank LD, Sando K \& Hill AG (1998) Optimal protein requirements during first two weeks after onset of critical illness. Critical Care Medicine 26, 1529-1536.

Jeevanandam M, Ali M, Holaday NJ \& Peterson SR (1995) Adjuvant recombinant human growth hormone normalizes plasma amino acids in parenterally fed trauma patients. Journal of Parenteral and Enteral Nutrition 19, 137-144.

Jimenez-Jimenez FJ, Ortiz-Leyba C, Morales-Menedez S, BarrosPerez M \& Munoz-Gracia J (1991) Prospective study on the 
efficacy of branched-chain amino acids in sepsis. Journal of Parenteral and Enteral Nutrition 15, 252-261.

Jurasinski CV, Gray K \& Vary TC (1995a) Modulation of skeletal muscle protein synthesis by amino acids and insulin during sepsis. Metabolism 44, 1130-1138.

Jurasinski CV, Kilpatrick L \& Vary TC (1995b) Amrinone prevents muscle protein wasting during chronic sepsis. American Journal of Physiology 268, E491-E500.

Jurasinski CV \& Vary TC (1995) Insulin-like growth factor I accelerates protein synthesis during sepsis. American Journal of Physiology 269, E977-E981.

Karinch AM, Kimball SR, Vary TC \& Jefferson LS (1993) Regulation of eukaryotic initiation factor-2B activity in muscle of diabetic rats. American Journal of Physiology 264, E101-E108.

Keys AB, Brozek J, Henschel A, Mickelsen O \& Taylor HL (1950) The Biology of Human Starvation. Minneapolis, MN: Minneapolis University Press.

Khan K, Wustemann M \& Elia H (1991) The effect of severe dietary restriction on intramuscular glutamine concentrations and protein synthesis rate. Clinical Nutrition 10, 120-126.

Kimball S, Jefferson L, Fadden P, Haystead T \& Lawrence J Jr (1996) Insulin and diabetes cause reciprocal changes in the association of eIF-4E and PHAS-I in rat skeletal muscle. American Journal of Physiology 270, C705-C709.

Kimball S, Jurasinski C, Lawrence J Jr \& Jefferson L (1997) Insulin stimulates protein synthesis in skeletal muscle by enhancing the association of eIF-4E and eIF-4G. American Journal of Physiology 272, C754-C759.

Kimball SR, Horetsky RL \& Jefferson LS (1998) Signal transduction pathways involved in the regulation of protein synthesis by insulin in L6 myoblasts. American Journal of Physiology 274, C221-C228.

Kimball SR \& Jefferson LS (1988) Effect of diabetes on guanine nucleotide exchange factor activity in skeletal muscle and heart. Biochemical and Biophysical Research Communications 156, 706-711.

Kimball SR \& Jefferson LS (1991) Regulation of initiation of protein synthesis by insulin in skeletal muscle. Acta Diabetologia 28, 134-139.

Kimball SR, Vary TC \& Jefferson LS (1992) Age dependent decreases in the amount of eukaryotic initiation factor 2 in various rat tissues. Biochemical Journal 286, 263-268.

Kimball SR, Vary TC \& Jefferson LS (1994) Regulation of protein synthesis by insulin. Annual Review in Physiology 56, 321-348.

Klimberg V \& Souba WW (1990) The importance of intestinal glutamine metabolism in maintaining a healthy gastrointestinal tract and supporting the body's response to injury and illness. Annals of Surgery 22, 61-76.

Lacey J \& Wilmore DW (1990) Is glutamine a conditionally essential amino acid? Nutrition Reviews 48, 297-310.

Lamphear BJ, Kirchweger JR, Skern T \& Rhoads RE (1995) Mapping of functional domains in eukaryotic protein synthesis initiation factor $4 \mathrm{G}$ (eIF-4G) with pircoviral proteases. Implication for cap-dependent and cap-independent translation initiation. Journal of Biological Chemistry 270, 21975-21983.

Lang CH, Fan, J, Cooney R \& Vary TC (1996) IL-1 receptor antagonist attenuates sepsis-induced alterations in IGF system and protein synthesis. American Journal of Physiology 270, E430-E437.

Levin DH, Ranu RS, Ernst V \& London M (1976) Regulation of protein synthesis in reticulocyte lysates. Phosphorylation of methionyl-tRNA binding factor by protein kinase activity of translational inhibitor isolated from heme-deficient lysates. Proceedings of the National Academy of Sciences USA 73, 2512-2516.
Li JB \& Jefferson LS (1978) Influence of amino acid availability on protein turnover in perfused skeletal muscle. Biochimica et Biophysica Acta 544, 351-359.

Lin T, Kong X, Haystead T, Pause A, Belsham G, Sonnenberg N \& Lawrence J (1994) PHAS-I as a link between mitogen activated protein kinase and translation initiation. Science 266, 653-656.

Lin T, Kong X, Saltiel AR, Blackshear PJ \& Lawrence JC (1995) Control of PHAS-I by insulin in 3T3-L1 adipocytes. Synthesis, degradation, and phosphorylation by a rapamycin-sensitive and mitogen-activated protein kinase dependent pathway. Journal of Biological Chemistry 270, 18531-18535.

Lynch CJ, Fox HL, Vary TC, Jefferson LS \& Kimball SR (2000) Regulation of amino acid-sensitive TOR signaling by leucine analogs in adipocytes. Journal of Cellular Biochemistry 77, 234-251.

Lynch CJ, Halle B, Fujii H, Vary TC, Wallin R, Damuni Z \& Hutson SM (2003) Potential role of leucine metabolism in leucine signaling pathway involving mTOR. American Journal of Physiology 285, E854-E863.

McDaniel M, Marshall C, Pappan K \& Kwon G (2002) Metabolic and autocrine regulation of the mammalian target of rapamycin by pancreatic $\beta$-cells. Diabetes $\mathbf{5 1}, 2877-2885$.

Morley SJ \& Traugh JA (1989) Phorbol esters stimulate phosphorylation of eukaryotic initiation factors $3,4 \mathrm{~B}$, and 4F. Journal of Biological Chemistry 264, 2401-2404.

Morley SJ \& Traugh JA (1990) Differential stimulation of phosphorylation of initiation factors eIF-4F, eIF-4B, eIF-3 and ribosomal protein S6 by insulin and phorbol esters. Journal of Biological Chemistry 265, 10611-10616.

Morley SJ \& Traugh JA (1993) Stimulation of translation in 3T3L1 cells in response to insulin and phorbol ester is directly correlated with increased phosphate labelling of initiation factor (eIF-) 4F and ribosomal protein S6. Biochimie 75, 985-989.

Naka S, Saito H, Hashiguchi Y, Lin MT, Furukawa S, Inaba T, Fukushima R, Wada N \& Muto T (1997) Alanylglutamineenriched total parenteral nutrition improves protein metabolism more than branched chain amino acid-enriched total parenteral nutrition in protracted peritonitis. Journal of Trauma 42, 183-190.

OldeDiamink SW, deBlaauw I, Deutz NE \& Soeters PB (1999) Effects in vivo of decreased plasma and intracellular muscle glutamine concentrations on whole-body and hindquarter protein kinetics in rats. Clinical Science 96, 639-646.

Oldfield S \& Proud CG (1992) Purification, phosphorylation and control of the guanine-nucleotide-exchange factor from rabbit reticulocyte lysates. European Journal of Biochemistry 208, 73-81.

Pause A, Belsham GJ, Gingras A-C, Donze O, Lin T-A, Lawrence JC Jr \& Sonenberg N (1994) Insulin-dependent stimulation of protein synthesis by phosphorylation of a regulator of 5'-cap function. Nature 371, 762-767.

Plank LD, Connolly AB \& Hill AG (1998) Sequential changes in the metabolic response in severely septic patients during the first 23 days after onset of peritonitis. Annals of Surgery 228, $146-158$

Rhoads RE (1993) Regulation of eukaryotic protein synthesis by initiation factors. Journal of Biological Chemistry 268, 3017-3020.

Rhoads RE, Joshi-Barve S \& Minich WB (1994) Participation of initiation factors in recruitment of mRNA to ribosomes. Biochimie 76, 831-838.

Scorsone KA, Panniers R, Rowland AG \& Henshaw EC (1987) Phosphorylation of eukaryotic initiation factor 2 during physiological stresses which affect protein synthesis. Journal of Biological Chemistry 262, 14538-14543.

Sherwin RS (1978) Effect of starvation on the turnover and metabolic response to leucine. Journal of Clinical Investigation 61, 1471-1481. 
Singh LP, Aroor AR \& Wabba AJ (1994) Phosphorylation of the guanine nucleotide exchange factor and eukaryotic initiation factor 2 by casein kinase II regulates guanine nucleotide binding and GDP/GTP exchange. Biochemistry 33, 9152-9157.

Sonenberg N (1994) Regulation of translation and cell growth by eIF-4E. Biochimie 76, 839-846.

Stehe P, Mertes N, Mertes N, Albers S, Puchstein C, Lawin P \& Furst P (1989) Effects of parenteral glutamine peptide supplements on muscle glutamine loss and nitrogen loss after major surgery. Lancet i, 230-233.

Stene JK \& Vary TC (1999) Nutritional aspects. In Anesthesia, 5th ed., pp. 2499-2531 [RD Miller, editor]. New York, NY, Churchill Livingstone.

Streat SJ, Plank LD \& Hill GL (2000) Overview of modern management of patients with critical injury and severe sepsis. World Journal of Surgery 24, 655-663.

Svanberg E, Frost RA, Lang CH, Isgaard J, Jefferson LS, Kimball SR \& Vary TC (2000) IGF-I/IGFBP-3 binary complex modulates sepsis-induced inhibition of protein synthesis in skeletal muscle. American Journal of Physiology 279, E1145-E1158.

Svanberg E, Moller-Loswick AC, Matthews DE, Korner U, Andersson M \& Lundholm K (1996) Effects of amino acids on synthesis and degradation of skeletal muscle proteins in humans. American Journal of Physiology 271, E718-E724.

Tessari P, Inchiostro S, Biolo G, Trevisan R, Fantin G, Marescotti MC, Iori E, Tiengo A \& Crepaldi G (1987) Differential effects of hyperinsulinemia and hyperaminoacidemia on leucine-carbon metabolism in vivo. Evidence for distinct mechanisms in regulation of net amino acid deposition. Journal of Clinical Investigations 79, 1062-1069.

Vary T, Dardevet D, Grizard J, Voisin L, Buffiere C, Denis P, Brueille D \& Obled C (1998a) Differential regulation of skeletal muscle protein turnover by insulin and IGF-I following bacteremia. American Journal of Physiology 275, E584-E593.

Vary TC, Dardevet D, Voisin L, Grizard J, Buffiere C, Denis P, Brueille D \& Obled C (1999a) Pentoxifylline improves insulin action limiting skeletal muscle catabolism following infection. Journal of Endocrinology 163, 15-24.

Vary TC, Jefferson LS \& Kimball SR (1999b) Amino acidinduced stimulation of translation initiation in rat skeletal muscle. American Journal of Physiology 277, E1077-E1086.

Vary TC, Jefferson LS \& Kimball SR (2001) Insulin fails to stimulate muscle protein synthesis in sepsis despite unimpaired signaling to 4E-BP1 and S6K1. American Journal of Physiology 281, E1045-E1053.

Vary TC, Jurasinski CV, Karinch AM \& Kimball SR (1994) Regulation of eukaryotic initiation factor 2 expression during sepsis. American Journal of Physiology 266, E193-E201.

Vary TC, Jurasinski CV \& Kimball SR (1998b) Reduced 40S initiation complex formation in skeletal muscle during sepsis. Molecular and Cellular Biochemistry 178, 81-86.

Vary TC \& Kimball SR (1992) Sepsis-induced changes in protein synthesis: differential effects on fast- and slow-twitch muscles. American Journal of Physiology 262, C1513-C1519.

Vary TC \& Kimball SR (2000) Effect of sepsis on eIF4E availability in skeletal muscle. American Journal of Physiology 279, E1178-E1184.
Vary TC \& Murphy JM (1989) Role of extra-splanchnic organs in the metabolic response to sepsis: effect of insulin. Circulatory Shock 29, 41-57.

Vary TC, Owens E, Beers JK, Verner K \& Cooney R (1996a) Sepsis inhibits synthesis of myofibrillar and sarcoplasmic proteins: modulation by interleukin-1 receptor antagonist. Shock $\mathbf{6}$, $13-18$.

Vary TC, Seigel JH, Placko R, Tall BD \& Morris JG (1989a) Effect of dichloroacetate on plasma and hepatic amino acids in sterile inflammation and sepsis. Archives of Surgery 124, 1071-1077.

Vary TC, Siegel JH \& Placko R (1989b) Pharmacologic modulation of increased release of gluconeogenic precursors from extra-splanchnic organs in sepsis. Circulatory Shock 29, 59-76.

Vary TC, Siegel JH, Tall BD \& Morris JG (1988a) Altered glucose regulation in sepsis revealed by partial reversal of PDH inhibition by dichloroacetate. Circulatory Shock 24, 3-18.

Vary TC, Siegel JH, Tall BD, Morris JG \& Smith JA (1988b) Inhibition of skeletal muscle protein synthesis in septic intraabdominal abscess. Journal of Trauma 28, 981-988.

Vary TC, Siegel JH, Zechnich A, Tall BD, Morris JG, Placko R \& Jawor D (1988c) Pharmacological reversal of abnormal glucose regulation, BCAA utilization, and muscle catabolism in sepsis by dichloroacetate. Journal of Trauma 28, 1301-1311.

Vary TC, Voisin L \& Cooney RN (1996b) Regulation of peptidechain initiation during sepsis by interleukin-1 receptor antagonist. American Journal of Physiology 271, E309-E316.

Vinnars E \& Hammervist F (1990) Role of glutamine and its analogs in post traumatic muscle protein and amino acid metabolism. Journal of Parenteral and Enteral Nutrition 14 125-129.

Voisin L, Gray K, Flowers KM, Kimball SR, Jefferson LS \& Vary TC (1996) Altered expression of eukaryotic initiation factor 2B in skeletal muscle during sepsis. American Journal of Physiology 270, E43-E50.

Wellbourne T (1995) Increased plasma bicarbonate and growth hormone after an oral glutamine load. American Journal of Clinical Nutrition 61, 1058-1062.

Wilmore DW (2000) Metabolic response to severe surgical illness: overview. World Journal of Surgery 24, 705-711.

Wilmore DW (2001) The effect of glutamine supplementation in patients following elective surgery and accidental injury. Journal of Nutrition 131, 2543S-2540S.

Windsor JA \& Hill GL (1988) Grip strength: a measure of the proportion of protein loss in surgical patients. British Journal of Surgery 75, 880-882.

Wustemann M, Tate N \& Elia H (1993) Effect of intramuscular glutamine concentration on muscle protein synthesis after injury using a constant infusion. Proceedings of the Nutrition Society 53, 59.

Yoshida S, Leskiw MJ, Scluter MD, Bush KT, Nagele RG, LanzaJacoby S \& Stein TP (1992) Effect of total parenteral nutrition, systemic sepsis, and glutamine on gut mucosa in rats. American Journal of Physiology 263, E368-E373.

Yoshizawa F, Kimball SR, Vary TC \& Jefferson LS (1998) Effect of dietary protein on translation initiation in rat skeletal muscle and liver. American Journal of Physiology 275, E814-E820. 